\title{
Research on the Web Application System Development Course Group for the Training of Innovation Talents
}

\author{
Yan-ling ZHOU \\ Department of Computer Science and Technology \\ Hefei University \\ Hefei, China \\ zhouyanling1006@163.com
}

\author{
Si-cheng ZHANG \\ Department of Computer Science and Technology \\ Hefei University \\ Hefei, China \\ zsc0373@163.com
}

\begin{abstract}
The paper analyzes the problems existing in the current university curriculum arrangement process, and focuses on cultivating innovative talents. The web application system development course takes the dominant position and other courses knowledge are the foundation for building the knowledge system. It mainly studies from three aspects including the knowledge integration, the practical teaching system construction and the teaching team construction and puts forward the curriculum-group construction structure for cultivating the innovative talents in the new situation so as to achieve the ultimate goal of forming a benign cooperation team which the learners can discuss, learn and cooperate from each other to realize the depth integration and internalization of the knowledge.
\end{abstract}

Keywords-Curriculum system; Knowledge fusion; Curriculum group; Practice teaching system; The teaching team

\section{INTRODUCTION}

In today's world, with the rapid development of the science and technology revolution, a new innovation wave is triggered. The party's 18 put forward the innovation-driven development strategy, fully relying on the innovation driven development and improving the quality and efficiency of the economy. Training the innovation-ability and high-quality talent becomes the important issues for the general higher education workers. In recent years, various universities have carried out a series of perform in many aspects such as the teaching methods, the teaching means and the examination methods [1], and the teaching methods such as inquiry, case type, debate and discuss are used synthetically in teaching process. Arouse students' curiosity and spirit of exploration and innovation [2], cultivate students' self-learning ability and ability to find and solve problems. However, in order to truly cultivate innovative talents, students must have a generous knowledge base [3]. At the same time, the development of network technology has made the web technology an indispensable part of today's society. All walks of life in society are advancing rapidly in response to the tide of Internet + . The web technology has become a necessary development skill for college students majoring in computer science in today's society. The course of web application system development is practical and comprehensive. This course covers a lot of content including two major technologies, Web client technology and Web server technology. Among them, the Web client technology including
HTML, CSS, JavaScript and the Web server technology including the Java language, the JSP technology and database technology, the Servlet technology, etc. Teaching goal is to enable students to master the dynamic website planning, establishment, management, maintenance and other related technology and operation skills, make the student to the dynamic, interactive Web application design have a comprehensive understanding, cultivate students using Web technology practice ability to develop the Web application system. At present, from the teaching present situation analysis of the core course about the web application system development, there are generally the following problems including the choice of teaching material is difficult, the time of the teaching classes is little, the course knowledge is much, the leading foundation is not solid, the teachers teaching is difficult, the test form is monotonous, the verification experiment is the main, lack of systematic and literacy training between related courses and the experiment teaching evaluation is not reasonable.

Therefore, in the paper, the web application system development curriculum is the core to train the ability of applied talents as the guidance, to study the innovative talent training system curriculum group construction of the web application development, cultivating applied talents with innovation ability and innovative thinking, so as to improve the students' professional practical ability and regional service ability, meet the needs of Internet + situation of talent. The paper is the teaching in the direction of Hefei College of computer science and technology department of network engineering construction and management. In combination with the talent-cultivation target under the new situation [4], the research is in three aspects including the knowledge integration, practical teaching system construction and teaching team construction. 


\section{The Study ON KNOWLEDGE Fusion}

One of the objectives of curriculum group construction is to eliminate the repeated content between courses, strengthen the inheritance of knowledge points and courses, and improve the implementation efficiency of the whole curriculum system. Periodically, the course group organizes and carries out thematic studies based on curriculum, focusing on majors, and focusing on the cultivation of talents. The curriculum system and construction goals of curriculum group construction are established in various forms, such as: visiting enterprises, inviting graduates to return visits, and college exchanges, etc. [5].The Web application system development course group consists of seven courses, as shown in figure 1 below.
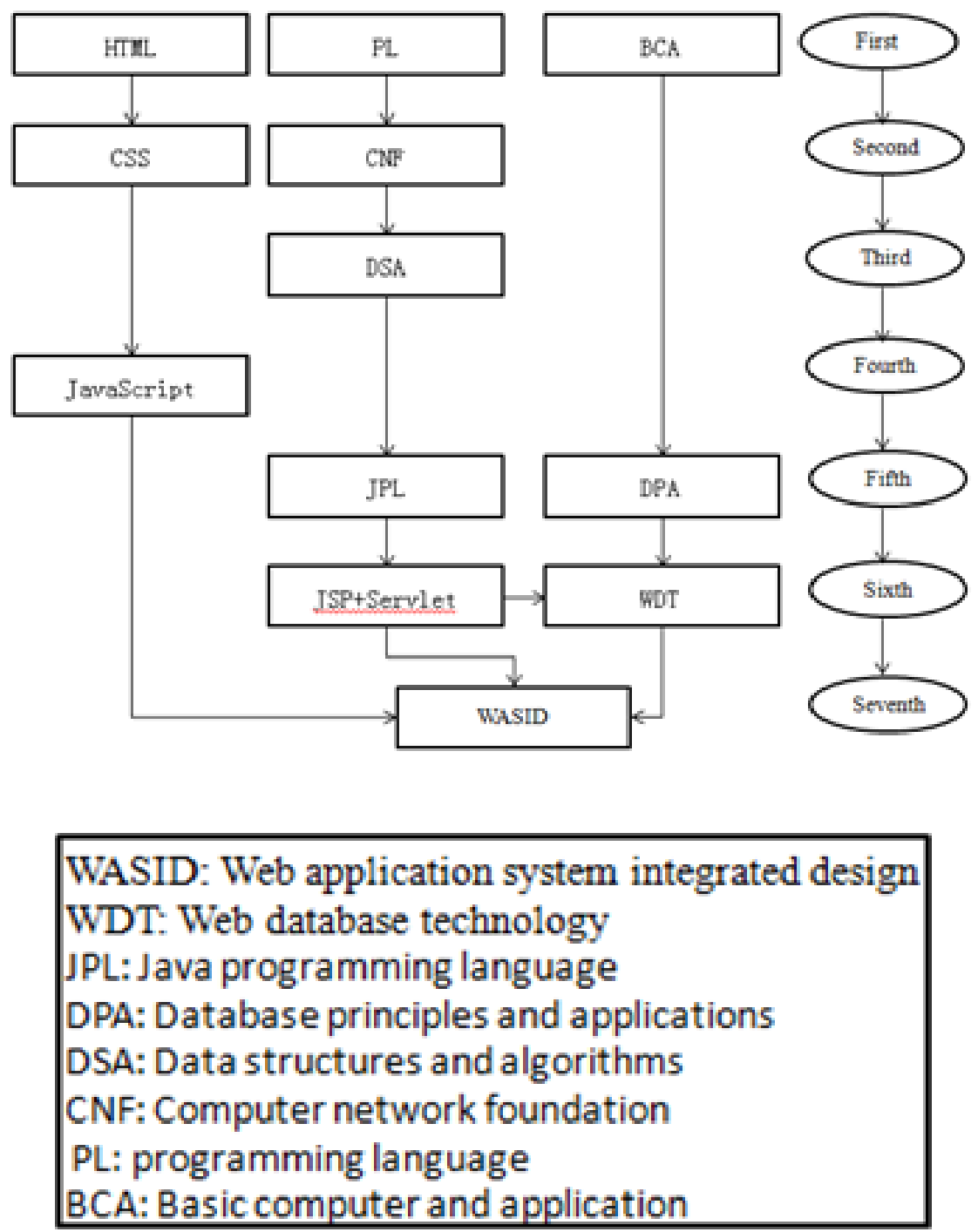

Fig. 1 Structure diagram of Web application system development course group

In Figure 1, the basic professional course of the network engineering is divided into seven stages. The HTML language foundation knowledge, program design language I and the computer and application are in the first semester because of the HTML doesn't need a tutorial. CSS and computer network are in the second semester because the leading course of CSS is HTML. The leading course of data structure and algorithms is programming language I, so it is in the third semester. The leading courses of JavaScript language are HTML language foundation, CSS foundation, data structure and algorithm, so it will be held in the fourth semester. The leading courses of Java language programming are programming language I and data structures and algorithms, so it is in the fifth semester together with database principles and applications. The leading course of JSP+Servlet is Java language programming, which can be put into the sixth semester. The comprehensive design of web application system is in the seventh semester in order to realize the comprehensive application of all professional courses of network engineering.

In the course group, on the basis of knowledge points, the position and role of each knowledge point in a course, as well as the correlation between the knowledge points before and after, are emphatically analyzed. In addition, analyze the different requirements and relations of a knowledge point in different courses. Because the focus in the same knowledge in different courses and requirements are different, it need the analysis to remove the repetition of knowledge points, and 
further clear that the nature of knowledge in different courses need to master the key to make the course study and practice goal of the different stages more clear and organized.

In addition to the integration of knowledge points, it is also necessary to further consolidate and deepen the integration of knowledge system in combination with school-enterprise union [6]. Enterprise is the pioneer transforming technology into productivity. Enterprise is the pioneer transforming technology into productivity, enterprise project resources and curriculum resources are rich in case platform, are truly the best case and combining theory with practice is more practical.

\section{RESEARCH ON THE CONSTRUCTION OF PRACTICAL TEACHING}

Practical teaching is a very important part of the teaching process. Practice not only plays an important role in consolidating theoretical knowledge and improving perceptual knowledge of course content, but also plays an important role in strengthening students' innovative engineering ability. In the practice teaching, students need learn the theoretical knowledge and practical engineering applications. It makes the students' practical operating ability, cooperation ability, the ability to combine theory and practice well digest. In the process of practical teaching, a complete set of practical teaching system should be formed to combine curriculum, professional direction and practical platform. Curriculum is the basis of practical teaching. In practice teaching, it is necessary to clarify the experimental objectives, experimental contents and technical specifications. The confirmatory experiment and operating configuration class is given priority in the classroom practice. The experiment can make the students deepen understanding of experimental content, master the use of the experimental development environment and complete the simple engineering plan design and implementation. Professional direction is the main line of practical teaching and the overall goal of talent training.

In the process of practice teaching, we should make full use of the online platform and integrated project, break traditional curriculum separately set the limits of the experiment, optimize the integration of experimental resources and do the drive type teaching with the engineering practice project close to living. Building new experiment system of Web application system development course must proceed from the training goal, take the student as the center, ability training as the guide, attach importance to the connection between the courses, and break the unidimensional relationship between the traditional courses. String together the knowledge points of the course, spread the knowledge across the course and use the current mobile and network technology to build the open and multiple-layered experimental teaching mode. Guide the students to master the basic theory of course and the relation of the course knowledge with each other systematically. At the same time, the curriculum knowledge permeates practice projects comprehensively. In practice, we make the students master new knowledge and new skill imperceptibly.

Figure 2 is for the Web application system development course of practical teaching system. It reflects a three-dimensional practice teaching system. It can promote the comprehensive development of students' knowledge, ability and quality by stimulating students' learning interest, collaborative factors. The abilities include system development ability, comprehensive application ability of knowledge, teamwork ability, problem analyzing and solving ability, innovation ability and social adaptability.

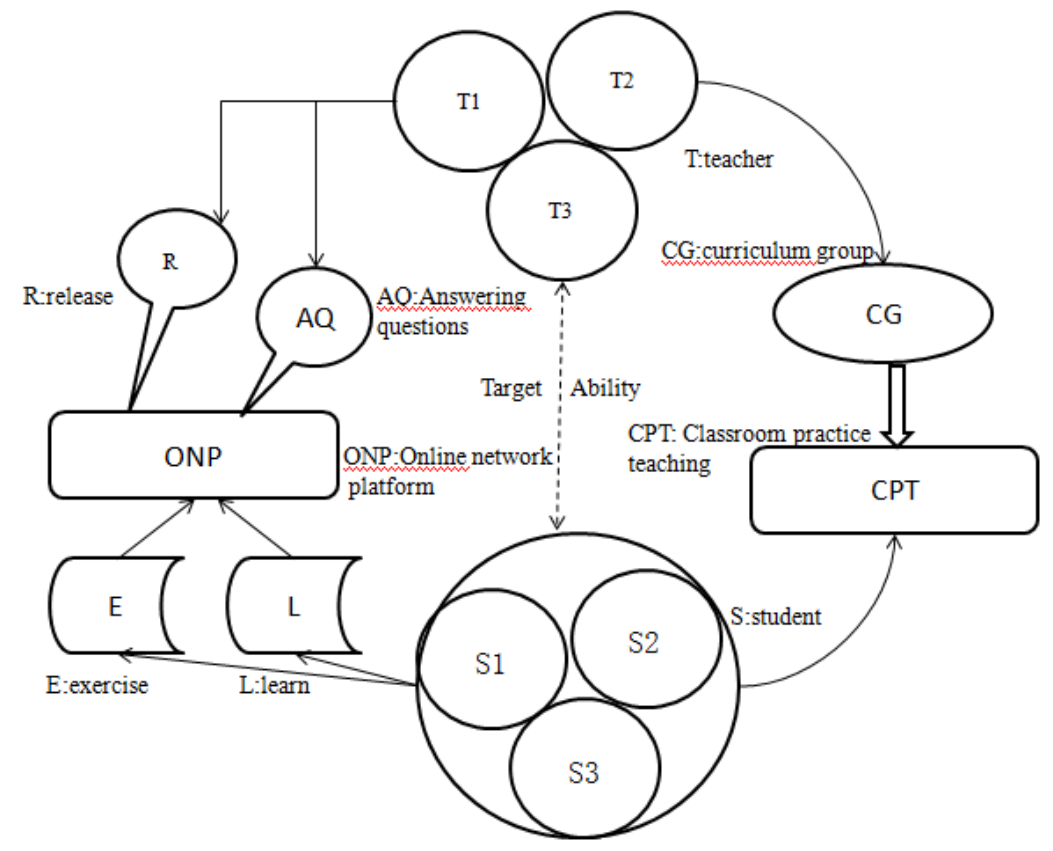

Fig. 2 Practical teaching system of web application system development course group

The teachers go on teaching in the form of teachers' team. The students learn the practical lesson in the form of student teams. The system reflects the team cooperation between teachers and students to promote a virtuous cycle of the system. The implementation of practice teaching adopts online network platform and classroom practice teaching. Among them, the 
online experiment platform is mainly the verification experiment of the curriculum group. The teacher team can guide students to login and practice learning platform for autonomous learning, to complete the experiment content through the release experiment teaching video, courseware, questions and so on. When the students find the problems in the learning and practicing, they can interact with the exchange of teachers in time through the network platform or smart phone and solve questions in experiment in order to grasp the basic theoretical knowledge and basic skills of the experiment. Through the network platform, the course content will be extended to the extra-curricular course. The learning autonomy is given to the students. The teacher can guide students to make full use of their spare time, to play the students' learning initiative and to realize the open learning space and time.

At the same time, in the practical teaching system with the core of the web application system development, students are in different grades and complete the same project. The infiltration of multiple courses and the comprehensive coverage of knowledge points are conducive to the cooperation between majors and industries, between students and students, and between students and teachers. In addition, teachers with different specialties can give targeted guidance to what they are good at in the project, so as to improve the teaching quality of practice. Under the guidance of teachers, students can consult materials, analyze problems, discuss problems and solve problems, which is more conducive to cultivating students' independent working ability and innovation ability.

\section{RESEARCH ON TEACHING TEAM BUILDING}

Team as an efficient way of work organization is applied widespread in enterprise management. Over the past few years, the team management concept has also been successful introduced into colleges and universities, the process of personnel training in colleges and universities have begun to pay attention to cultivate the students' ability of team. In the construction of teaching teams, curriculum groups should take the construction of teachers' teams as the core, and explore the comprehensive construction platform of teachers' and students' teams, students' teams and school-enterprise teams.

In the process of teaching team construction, the teaching of curriculum group is as platform. The teachers are closely linked to the inner in the subject of the research direction and should reach a consensus on the goals and tasks of the talents cultivation. The curriculum group based on web application system development puts the professional direction as a platform, regards the courses and knowledge group as a support with double teacher training, strengthens the unity of scientific research and teaching and forms a basic stability of teacher team. In addition, through the cooperation between colleges and experience, it can train teachers' engineering practice experience, improve teachers' practical ability, enhance the confidence of teachers in the teaching and help to achieve better teaching effect. On this basis, teachers are encouraged to engage in scientific research. Scientific research and teaching complement each other. The improvement of scientific research level also promotes the improvement of teaching level.

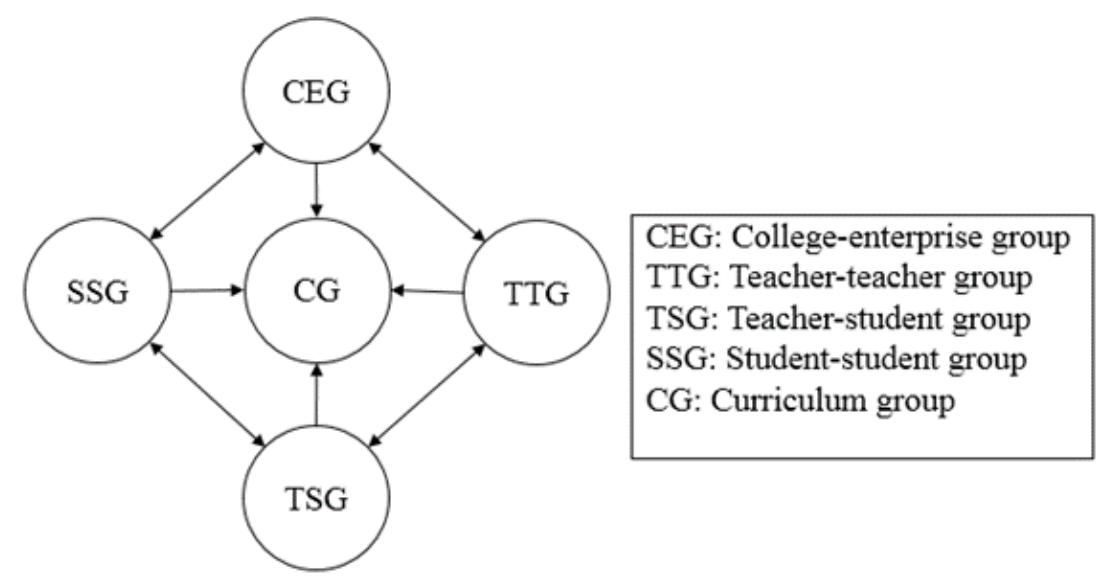

Fig. 3 Group system structure diagram of the teaching team

In figure 3 , this group system is a circular system. The group system in the teaching team consists of five parts, including course group, school enterprise group, teacher group, teachers and students group and student group. Among them, the course group is the core of this system. Other groups serve the course group, and the group and the other group are mutually dependent and complementary. In the process of building the teachers' group, we have drawn lessons from the experience of school-enterprise cooperation. Meanwhile, we have got feedback from teachers and students in the process of leading the students' team practice. The student-student group is continuously improved the practical ability of the student team and the ability to analyze and solve problems under the joint action of the school-enterprise group and the teacher-student group. Under the feedback from the student-student and teacher-teacher groups, the school-enterprise group constantly updates and supplements the new more practical and efficient school-enterprise cooperation project content, which is more conducive to education and teaching work. Thus it can truly form complementary advantages, the close collaboration of team work and study atmosphere, provide an individual teacher learning from each other, improve together development platform, to make teachers gradually changing education concept, improve vocational education teaching ability, sublimation professional spirit, so that the overall quality of the 
teaching team can be improved, and it can maximize its role of radiation and demonstration.

\section{CONCLUSION}

In the course group of web application system development oriented to the training of innovative talents, in the aspect of theoretical teaching, the knowledge system of system course group is constructed to realize the integration of knowledge. Dominated by the web application system development course knowledge and based on knowledge points for other courses, we build the system of knowledge. At each semester and each phase, we can deepen the reform of the teaching content knowledge system, further do curriculum group of knowledge integration, at the same time, through the cooperation between colleges and enterprise to achieve the integration of knowledge of and consolidate. In practice teaching, a complete set of practice teaching system is formed. This system is a comprehensive curriculum system of theory and practice, which requires teamwork. System development teams can be formed by the teachers also can be formed by students freely and the ultimate goal is to form a benign cooperation team. They make progress together in the discussion; learn from each other and mutual competition so as to realize the depth of knowledge integration and internalization. In the construction of teaching team, a stable, solid and sustainable teaching team should be established. The construction of teachers' team in the teaching group is the core part of the construction of teaching team. While the construction of teachers' team, the comprehensive construction platform of teachers' team and students' team is constantly explored. With courses and knowledge groups as the support, the dual teacher training should be taken into account, and the unity of scientific research and teaching should be constantly strengthened to form a basically stable teacher team. To promote the real transformation of teaching and knowledge into social productivity by the way that teachers drive students.

\section{ACKNOWLEDGEMENT}

This paper is supported by Natural science fund project from the department of education of Anhui province (KJ2016A609), Higher Education Quality Engineering of Anhui Province (2015ckjh061, 2015zy054, 2017mooc318), Higher Education Revitalization Plan Major Teaching Reform Project of Anhui Province (2015zdjy141), Teaching Team of Anhui Province (2016jxtd101), Outstanding Talent Education Training Plan of Anhui Province (2015zjjh026).

\section{REFERENCES}

[1] Zhang Rongguo, Li Fuping, Zhang sulan. The core curriculum group construction research of the computer professional in University [J]. Journal of computer education, 2015(9): 64-67.

[2] Jia Yunpeng, Guo Ning. The application and fusion of exploring practice teaching mode in application [J].Journal of Beijing university of posts and telecommunications (social science edition), 2016, 19 (1) : 107-112.

[3] Zhang Jing. Applied innovative talents training mode research based on the education informatization [J].Journal of north China university (social science edition), 2015 (4) : 149-151.

[4] Chen Zuocong, Qu MingXin. The innovative personnel training mode research of the applied undergraduate network engineering professional [J]. Computer education: 2015(4): 4 -7.

[5] Jing shanshan, sun lijuan, Sun Runyuan. The application research of pushing forward the reform of practice teaching mode in tutorial system [J]. Journal of computer education, 2013 (14): 33-36.

[6] Cai Wenfen, Guo Xiang, Cheng Miao. The exploring application-oriented undergraduate training based on the university-enterprise cooperation mode [J]. Journal of Qiqihar university, 2015 (7): 158-160. 